Journal of Social Sciences 8 (3): 304-309, 2012

ISSN 1549-3652

(C) 2012 Science Publications

\title{
Contact with Nature and Children's Wellbeing in Educational Settings
}

\author{
${ }^{1}$ Giuseppe Carrus, ${ }^{2}$ Sabine Pirchio, ${ }^{2,3}$ Ylenia Passiatore, \\ ${ }^{1}$ Stefano Mastandrea, ${ }^{3}$ Massimiliano Scopelliti and ${ }^{1}$ Gabriella Bartoli \\ ${ }^{1}$ Department of Cultural and Educational Studies, \\ Experimental Psychology Laboratory, Faculty of Education, \\ University of Roma Tre, Italy \\ ${ }^{2}$ Department of Dynamic and Clinical, \\ Faculty of Psychology SAPIENZA University of Rome, Italy \\ ${ }^{3}$ Department of Human Science, \\ Faculty of Education LUMSA University, Rome, Italy
}

\begin{abstract}
Problem statement: The study explores the role of the spatial-physical features of the environment for the functioning of educational institutions. Previous research in the field of environmental psychology showed how physical characteristics of learning environments might be linked to positive or negative outcomes in terms of learning attitudes and behaviors. In particular, there is consistent empirical evidence showing that contact with natural settings promotes psychological restoration, leading to the recovery of direct attention and stress reduction. The present study aims at investigating the impact of the experience of contact with external green spaces during school time upon children's capacity of focusing direct attention on a specific task during structured activity with educators and upon the quality of children's social interaction with peers and adult educators. Approach: A total of 16 children (age range 18-36 months) attending a recently opened childcare center in Rome, Italy participated in the study. The physical features of the internal and external spaces of the educational institutions were assessed via on-site observations. Systematic observations of the children were performed, in different spaces of the educational setting and in different moments of the school day. In particular, children's performance in a visual-spatial task requiring direct attention and children social behavior (using a checklist of social interaction and emotional behavior) were assessed by a paper-andpencil observation grid on a six-step scale. Results: The research suggests that contact with external green open spaces during school time is significantly associated with better performances in structured tasks requiring direct attention and to positive social behaviors. The frequency of educators' direct interventions is smaller after the children's contact with external green open spaces. Conclusion/Recommendations: These findings can contribute to gaining a better understanding of the restoration processes occurring in different typologies of educational settings and suggest the importance of providing these environments, such as childcare centers, with adequate external green spaces, in order to allow children to have opportunities for systematic psychological restoration during school time.
\end{abstract}

Key words: Providing educational settings, psychological restoration, direct attention, custom-made environment, adequate external green, Stress Reduction Theory (SRT)

\section{INTRODUCTION}

The physical environment of educational settings. Because of social and cultural changes in contemporary society, attendance to childcare centers and infant schools is becoming an increasingly frequent experience in the later decades, not only for the children of working parents (Musatti, 2004). As a consequence, recent developments in psychological and educational research tend to consider the childcare centers and infant school not only as a service for child protection and physic care when the parents are away, but rather as a real educational institution, where children should adequately develop their psychological and relational

Corresponding Author: Giuseppe Carrus, Department of Cultural and Educational Studies, Experimental Psychology Laboratory, Faculty of Education, University of Roma Tre, Italy 
skills in a custom-made environment (Musatti, 2004; Young et al., 1997).

However, the education experience of the children in child-care centres and infant schools is qualitatively different from their experience at home and presents both positive and problematic aspects. On the one hand, presence of peers, multiples attachment's relations with educators and diversified experiences are aspects that characterize these educative institutions and that might positively contribute to the child's growth (Galardini, 2003). On the other hand, the children experience in these settings can be characterized by a moderate-tohigh level of psychological and physical distress, due to the temporary distance from the parents and the more familiar home environment (Legendre, 2003).

In addition to the important role of educators, a crucial factor for an optimal functioning of educative institutions such as child-care centres and infant schools is represented by the spatial and physical characteristics of the environments where the activities of children and educators take place. School environments can in fact be considered as the 'third educator', in addition to peers and the educators (Spielberger, 2004).

Within psychological research, the importance of the socio-physical environment in human psychological processes, behaviour and wellbeing has been emphasized by studies in the field of environmental psychology (Bechtel and Tsertsman, 2002; Spielberger, 2004). Indeed, as it is long known form earlier research on school environments and educational functioning, well-designed schools might be the basis for the development of more incisive and effective learning models and outcomes (Bechtel and Tsertsman, 2002; Spielberger, 2004; Weinstein, 1979). Schools that fit to the requirements of an appropriate design should encourage the possibility for the children to interact with the surrounding environment, stimulate their creativity, promote individual autonomy and facilitate the performance of group works.

Traditionally, the majority of studies addressing this topic investigated the role of the physical environment with reference to primary and secondary schools (Evans and McCoy; 1998; Bechtel and Tsertsman, 2002; Spielberger, 2004; Weinstein, 1979; Provost et al., 1991). However, it is arguable that the importance of the physical features of education settings will be considerable also in the case of preschool children and infants, since these are particularly sensitive to the external stimuli and dependent from the environment for their cognitive, affective, behaviour and communicative development (Baroni, 2008). Nevertheless, few researches have explicitly investigated this with reference to younger children
(Campos-De-Carvalho and Rossetti-Ferreira, 1993; Legendre, 1999; 2003).

Towards restorative educational environments: Previous works in environmental psychology has identified some specific characteristics of the environments that can be defined as 'restorative'. Restorative environments are in fact defined as those environments that are able to promote and not only to permit, the recovery of those mental and physical capacities depleted during daily life activities, such as the abilities to focus direct attention and to cope with stress (for a review, see Spielberger, 2004). Typically, research in this field showed that the natural environments are more restoratives than built ones and that the experience of contact with the nature, as well as the activities that can take place therein, promote psychological and physical well-being (Spielberger, 2004; Berg et al., 2007). Earlier studies showed that even visual access to natural scenes from hospital windows might reduce patients' recovery from surgery (Ulrich, 1984).

According to research in this field, the process of psychological restoration is strictly connected to the experience of restorative environments, implying the possibility for relaxation, clearing one's minds and taking some distance from ordinary aspects of life. Two main theoretical frameworks have been proposed to account for positive outcomes deriving from person-environment transactions, both assuming an evolutionary perspective and assigning a central role in the restoration process to the relationships with natural environments.

A first one is the Stress Reduction Theory (SRT) Altman and Wohlwill (1983). SRT postulates that the human evolution took place in touch with nature and natural selection operated so to advantage in the competition for survival those individuals more prone to positively react to natural environments. This evolutionary explanation was later on incorporated also into the so-called biophilia hypothesis (Kellert and Wilson, 1995). A positive reaction implies an aesthetic response, involving preference and pleasure, which in turn promotes approaching and exploration of the environment. In this perspective, person-nature relationship would have an even greater adaptive function if coming in touch with natural environments would also be able to reduce stress, which makes individuals less effective in everyday behaviour. The stress reduction effect of person-nature relationship, hypothesized by Altman and Wohlwill (1983), was confirmed in a variety of experiments in which psychophysical (e.g., cortical activity, heart rate, blood 


\section{J. Social Sci., 8 (3): 304-309, 2012}

pressure, skin conductance,) and psychological (affective states, e.g., fear, anger, attention, sadness,) measures of stress were considered (Ulrich et al., 1991; Hartig et al., 1991; 2003). These studies, often employed a pre-post design, based on a comparison of stress reduction for respondents in different experimental conditions, namely the vision of-or experience in-natural vs. built environments. Hartig et al. (1991), in particular, showed the consequences of stress for actual behaviour in a study employing a performance task requiring direct attention; better performances emerged for subjects in the "natural" condition.

A second theoretical model of psychological restoration in nature is the Attention Restoration Theory (ART) by Kaplan and Kaplan (1989). A central issue of ART is the concept of compatibility between the environment and its users (Kaplan, 1983), involving the possibility for the environment to support people's inclination, cognition and reflection, so promoting personal control and adaptive behaviours. In this respect, restorative environments allow people to regain a condition of effective cognitive functioning, which is often lost in a variety of everyday activities/situations leading to mental fatigue. A key role in ART is played by directed attention, a psychological concept that can be traced back to the very earlier stages of scientific psychological research (James, 2001). Directed attention implies the possibility for people to focus on a variety of potentially uninteresting, albeit important to attend, stimuli. For this mechanism to be effective, some effort is needed, because all the potential distractions have to be warded off. The consequence is that it is vulnerable to fatigue. In the ART perspective, the recovery of this adaptive mechanism can be gained by exposition to stimuli which are interesting in themselves, so that using directed attention becomes temporarily unnecessary. Kaplan (1995) states that "only in the modern world the split between the important and the interesting has become extreme", because "what was important to evolving human was innately fascinating and thus does not require directed attention" (p.170). Natural environments are innately fascinating, because all their stimuli have to do with survival and the use of directed attention in such a typology of environments is simply not required. As a consequence, nature is the best place in which restoration processes are likely to occur.

According to ART, there are four distinctive characteristics that can be recognized by individuals and that can be identified as restorative properties of an environment: being away, fascination, extent and compatibility. Being-away implies a change of scenery and/or experience from daily routines, promoting a conceptual-rather than a merely physical - distance from the ordinary. A new environment is not restorative in itself; restoration processes are fostered when pressures and obligations of everyday life are left apart in person-environment interaction. Fascination is intended as the capability of environments to involuntarily elicit individual's attention, without requiring mental effort. Extent refers to the properties of connectedness and scope in environments. On the one hand, restoratives environments should be perceived as systems where all elements are coherently related each other. On the other hand, they should be perceived as extended enough to engage individual's mind, thus promising much more to explore beyond the immediate perception. Compatibility has to do with the level of perceived congruence between the characteristics of the environment and people's needs, intentions and inclinations.

On the basis of these research findings, it can be argued that two crucial factors that an effective educational setting should have are related to the capacity of promoting psychological restoration, through reducing stress and maintaining (or recovering) direct attention. These two factors appear in fact closely linked to psychological variables related to children cognitive development and well-being. Stress reduction is important, for example, to encourage a positive social climate in the class. Social climate, in turn, is important to reduce aggressive behaviours among the schoolmates and to encourage working autonomy, as highlighted by the seminal studies of Lewin et al. (1939) already in the'30s.

Likewise, attention restoration is important for children's performance. When referring to pre-school children, the term performance does not refer to children production adequacy, but to their capacities of remaining concentrate for a sufficient amount of time in the execution of structured activities with educators: these activities are in fact very important for the children cognitive development (Fabio, 2001).

In educational settings, the effect of children's experiences of contact with natural features has not been extensively explored. A study by Grahn (1997) suggests that contact with the nature has important effects on children motor coordination and attentive abilities. Other studies also revealed how access to nearby nature is important for the cognitive, affective and relational development of children and adolescents (Coley et al., 1997; Wells, 2000; Wells and Evans, 2003).

As the pre-school experience can be characterized by moderate-to-high stress levels (Legendre, 2003), it seems then particularly important to investigate whether and how, contact with restorative natural environments 
during the daily educational activities might promote and restore an effective cognitive functioning and overall well-being in children.

\section{MATERIALS AND METHODS}

Context of the study, aims and hypotheses: The main aim of this study is to investigate how the spatial physical characteristics of education environments such as child-care centres may have an impact upon children's wellbeing, as well on pre-school learning process. In particular, we investigated in this study environmental factors referring to the characteristics of external spaces, with reference in particular to the presence of the garden and of the green areas therein. Characteristics of internal spaces, such as formal and chromatic aspects of the interior design, visual openness/closure, transparency of walls and dividing elements, have been also controlled for. Based on the environmental psychological theories and research on restorative environments, we generally argue here that contact with external green spaces during school time might be reflected in the affect cognitive and affective development of preschool children's. In particular, we focus in our study on processes such as direct attention restoration and interpersonal behaviour with peers and adults, in different moments of the day and in relation to different activities (i.e., structured activities with educators and free play).

In sum, the specific aims of the study are:

- The assessment of the external spatial physical characteristics of the child-care settings (presence, extension and typology of the garden and external green, typologies of external furniture)

- The observation of the children in different contexts and times of the day at school; specifically, the performances of the children in classroom structured activities were compared after free play activities in the internal vs. external green space, respectively

In line the literature reviewed so far, our general hypotheses is that an adequate presence of external green areas, allowing children to have positive experiences of contact to nature in their daily activities will be reflected in an higher capacity of children to focus their attention during the structured activities in the classroom. We also expect that these positive experiences of contact to nature will be reflected in a better quality of children's social interaction with peers and adult educators (e.g., less frequent expressions of negative emotions such as crying and anger, less frequent helping requests to educators).
Participants, research design and procedure: The study involved a total of 16 children participated to the study, of age ranging between 18 and 36 months, attending a recently opened (February 2010) private child-care centre, located in the suburban neighbourhood of Ostia Antica, run in agreement with the Rome municipality.

Prior to the main study, preliminary interviews with child-care personnel were conducted in order to ascertain the main characteristics of the usual daily routines that took place in the child-care centre considered. This preliminary phase allowed to identify two key moments in the children's usual routines: structured activities with educators and free play.

In particular, two different crucial moments of free play were identified, which served as the main research design factor in our study: free play within the interior spaces of the child-care building and free play in the external green spaces. The children's performance in a visual-spatial tasks and the quality of the children's social interaction with peers and educators during free play activities and during structured activities, after children's free play, occurring in the internal Vs. external green space, respectively, were then compared to test our hypotheses.

Measures: As stated, the performance of children in a visual spatial task was used as an indicator of children's capacity of using direct attention: children were asked to colour with a pencil a drawing provided by the educators (or to stick small pieces of coloured paper with the glue, in the case of 36-months children), without going beyond the drawing outlines. Performances were then evaluated by two independent coders, with an inter-rating agreement score of $100 \%$ and dummy coded (task accomplished vs. not accomplished).

In addition to that, the quality of children social interaction with peers and educators was measured through the following indicators:

- Frequency of small group play

- Frequency of self-organized play

- Frequency of direct interventions by educators (reverse coded)

- Frequency of boredom feelings episodes (reverse coded)

Finally, the following indicators were used to assess children's level of stress:

- Frequency of dispute-resolution interventions by educators 
- Frequency of crying episodes

- Capacity of being quickly comforted in case of crying (reverse coded)

Scores on all these indicators were recorded by a trained observer through a paper-and-pencil observation grid and were coded on a six-step scale, ranging from 0 $=$ never to $5=$ always.

\section{RESULTS}

Effects of contact with external green space on positive social relations and stress reduction: Results seem to confirm also our main hypothesis on the effects of contact with external green space on positive social relations with peers and educators and on children's stress, as highlighted by a series of t-tests. As expected, in the external green play condition, compared to the internal one, a significantly higher frequency of both small group play $\left[\mathrm{t}_{(9)}=2.36 ; \mathrm{p}=0.02\right]$ and selforganized play $\left[\mathrm{t}_{(9)}=2.36 ; \mathrm{p}=0.03\right]$ was detected. Also, with a strong tendency to significance, results show a lower frequency of direct interventions by educators $\left[\mathrm{t}_{(9)}=-1.42 ; \mathrm{p}=0.09\right]$ and of boredom feelings episodes $\left[\mathrm{t}{ }_{(9)}=-1.48 ; \mathrm{p}=0.09\right]$ during free play in the external green space compared to internal built space.

Finally, a series of mixed model ANOVAs was performed to test the hypotheses on stress reduction indicators. In this case, we expect a significant 2-way interaction, as children should exhibit better scores only in the observations carried out on the structured activities occurring after external green free play (vs. internal built free play) and not before. The expected 2way interaction turned out to be significant, in the predicted direction, for the following indicators: frequency of dispute resolution interventions by educators $\left[\mathrm{F}_{(1,9)}=7,63 ; \mathrm{p}=0.022\right.$; eta square $\left.=0.46\right]$; frequency of crying episodes $\left[F_{(1,9)}=4,46 ; p=0.064\right.$; eta square $=0.33]$; and capacity of being quickly comforted in case of crying $\left[\mathrm{F}_{(1,9)}=9,17 ; \mathrm{p}=0.014\right.$; eta square $=0.50]$.

Effects of contact with external green space on performance in visual spatial tasks: In line with our hypotheses, children seemed exhibited a higher accuracy in the performance of the visual-spatial tasks when previously exposed to external green spaces for free playing activities, compared to when previously exposed to interior built spaces for free playing activities. In fact, the number of correctly executed tasks was above $50 \%$ in the green free play condition and below $50 \%$ in the interior free play condition.

\section{DISCUSSION}

Taken together, our preliminary results seem to confirm how the fruition of green external open spaces in educational settings might have a positive impact on preschool children social behaviours and performances, although with apparently grater clarity in the domain of stress reduction; results concerning the capacity of focusing direct attention are less clear.

More generally, our results could help shed some light on research about restorative environments, as they can contribute to gain a better understanding of the restoration processes occurring in different typologies of educational settings among younger children.

From a practical point of view, our findings suggest how educational settings for younger children, such as day-care centres, should be provided with an adequate amount of external green spaces, because of the important role that these might have in promoting the recovery of direct attention and stress reduction. Because of the limited number of subjects in our samples, our findings need however to be replicated with a larger sample and in different geographical contexts to enhance their external validity. In addition, a comparison with educational settings showing a lower amount of green external open spaces should be made.

\section{CONCLUSION}

To conclude, the relationship between spatialphysical features of educational institutions and child's wellbeing could also be moderated by appropriate trainings addressed to educators, in order to inform and provide them with the necessary knowledge and instruments to adequately exploit all the resources available in the educative institutions.

\section{REFERENCES}

Altman, I. and J.F. Wohlwill, 1983. Behavior and the Natural Environment. 1st Edn., Plenum Press, New York, ISBN: 0306410990, pp: 346.

Baroni, M.R., 2008. Psicologia Ambientale. 2nd Edn., Il Mulino, Bologna, ISBN: 8815125965, pp: 184.

Bechtel, R.B. and A. Tsertsman, 2002. Handbook of Environmental Psychology. 1st Edn., John Wiley and Sons, New York, ISBN: 0471405949, pp: 722.

Berg, A.E.V.D., T. Hartig and H. Staats, 2007. Preference for nature in urbanized societies: Stress, restoration and the pursuit of sustainability. J. Soc. Issues, 63: 79-96. DOI: $10.1111 / \mathrm{j} .1540-$ 4560.2007.00497.x 
Campos-De-Carvalho, M.I. and M.C. Rossetti-Ferreira, 1993. Importance of spatial arrangements for young children in day care centers. Children's Environ., 10: 19-30.

Coley, R.L., W.C. Sullivan and F.E. Kuo, 1997. Where does community grow? The social context created by nature in urban public housing. Environ. Behav., 29: 468-494. DOI: 10.1177/001391659702900402

Evans, G.W. and J.M. McCoy, 1998. When building don't work: The role of architecture in human health. J. Environ. Psychol., 18: 85-94. DOI: 10.1006/jevp.1998.0089

Fabio, R.A., 2001. L'attenzione: Fisiologia, Patologie e Interventi Riabilitativi. 3rd Edn., FrancoAngeli, Milano, ISBN: 884643272X, pp: 202.

Galardini, A.L., 2003. Crescere al Nido. Gli Spazi, i Tempi, le Attività, le Relazioni [Growing at the Nursery. 1st Edn., Carocci, Roma, ISBN: 8843025546, pp: 196.

Grahn, P., 1997. Ute på dagis. 1st Edn., Movium, Alnarp, ISBN: 915765199X, pp: 111.

Hartig, T., G.W. Evans, L.D. Jamner, D.S. Davis and T. Garling, 2003. Tracking restoration in natural and urban field settings. J. Environ. Psychol., 23: 109-123.

Hartig, T., M. Mang and G.W. Evans, 1991. Restorative effects of natural environment experiences. Environ. Behav., 23: 3-26. DOI: 10.1177/0013916591231001

James, W., 2001. Psychology: The Briefer Course. 1st Edn., Courier Dover Publications, Mineola, New York, ISBN: 0486416046, pp: 352.

Kaplan, R. and S. Kaplan, 1989. The Experience of Nature: A Psychological Perspective. 1st Edn., CUP Archive, Cambridge, New York, ISBN: 0521341396, pp: 340.

Kaplan, S., 1983. A model of person-environment compatibility. Environ. Behav., 15: 311-332. DOI: 10.1177/0013916583153003

Kaplan, S., 1995. The restorative benefits of nature: Toward an integrative framework. J. Environ. Psychol., 15: 169-182. DOI: 10.1016/02724944(95)90001-2

Kellert, S.R. and E.O. Wilson, 1995. The Biophilia Hypothesis. 1st Edn., Island Press, Washington, ISBN: 1559631473, pp: 496.
Legendre, A., 1999. Interindividual relationships in groups of young children and susceptibility to an environmental constraint. Environ. Behav., 31: 463-486. DOI: 10.1177/00139169921972191

Legendre, A., 2003. Environmental features influencing Toddlers' bioemotional reactions in day care centers. Environ. Behav., 35: 523-549. DOI: 10.1177/0013916503035004005

Lewin, K., R. Lippitt and R.K. White, 1939. Patterns of aggressive behavior in experimentally created social climates. J. Soc. Psychol., 10: 271-299. DOI: 10.1080/00224545.1939.9713366

Musatti, T., 2004. Early educational settings in Italy: The social context and educational prospects. Prospects, 34 : 447-456. DOI: 10.1007/s11125005-2716-3

Provost, M.A., D. Garon and R. LaBarre, 1991. Social adjustment of young children of preschool age in relation to continuity of day care. Canadian J. Behav. Sci., 23: 183-194. DOI: 10.1037/h0078997

Spielberger, C.D., 2004. Encyclopedia of Applied Psychology. 1st Edn., Academic Press, New York, ISBN: 0126574103, pp: 3200.

Ulrich, R.S., 1984. View through a window may influence recovery from surgery. Science, 224: 420-421. PMID: 6143402

Ulrich, R.S., R.F. Simons, B.D. Losito, E. Fiorito and M.A. Miles et al., 1991. Stress recovery during exposure to natural and urban environments. J. Environ. Psychol., 11: 201-230.

Weinstein, C.S., 1979. The physical environment of the school: A review of the research. Rev. Educ. Res., 49: 577-610.

Wells, N., 2000. At home with nature. Effects of "greenness" on children's cognitive functioning. Environ. Behav., 32: 775-795.

Wells, N.M. and G.W. Evans, 2003. Nearby nature: A buffer of life stress among rural children. Environ. Behav., 35: 311-330.

Young, T.K., W.K. Marsland and E. Zigler, 1997. The regulatory status of center-based infant and toddler child care. Am. J. Orthopsychiatry, 67: 535-544. PMID: 9361860 